\title{
CAMBIO CLIMÁTICO: IMPUESTOS SOBRE EL CARBONO, COSTE Y EFICIENCIA ECONÓMICA
}

\author{
Cristina García Fernández
}

Universidad Complutense de Madrid

http://dx.doi.org/10.5209/rev_NOMA.2012.v34.n2.40734

Resumen.- La finalidad de este trabajo es discutir, desde un marco teórico, las políticas económicas más efectivas que pueden emplearse en frenar los impactos del cambio climático. Con este fin se analizan los instrumentos e incentivos económicos más adecuados para ralentizar el avance del calentamiento global, a la vez que se realiza una comparación entre los mismos en relación a su eficiencia económica y bajo diferentes criterios. El caso del impuesto sobre el carbono tendrá un tratamiento especial al ser el incentivo que logra una mayor eficiencia en el mercado.

Palabras clave.- impuestos sobre el carbono, permisos de emisiones

\begin{abstract}
The purpose of this paper is the discussion, in a theoretic frame, of the most effective economic policies that could be employed to slow the impacts of climate change. Our aim is then to present most adequate economic instruments that are capable to slowing down the global warming rate of increase. We also make a comparison between those instruments in relation to their economic efficiency below different criteria. The case of a carbon tax has a special treatment in this paper due to the efficiency it shows in the market.
\end{abstract}

Keywords.- carbon taxes, tradable emissions permits

JEL classification: H41, Q51, Q54

\section{Introducción}

Hoy en día, disponemos de diversas políticas económicas de tipo preventivo destinadas a reducir las emisiones de gases de efecto invernadero. La literatura existente suele definir a estas políticas como coste-eficientes ya que pueden (Clarke, R el al, 1996) lograr una reducción importante de emisiones sin tener que incurrir en un coste muy alto. Del mismo modo, estas políticas también son coste efectivas siempre que no sólo consigan recortes importantes de emisiones del gas mayormente emitido a la atmósfera, sino también de otros gases de efecto invernadero. Por ejemplo, aumentar la eficiencia energética no sólo reduce las emisiones de dióxido de carbono sino también de otros gases que contribuyen altamente al calentamiento global. Pero además, una mayor eficiencia puede hacer que las industrias y los países se tornen más competitivos en los mercados internacionales. Ahora bien, las políticas económicas destinadas a mejorar la eficiencia energética, para que sean efectivas, necesitan el apoyo del público y de los grupos de interés, esto es, los gobiernos no pueden ser los únicos que tomen partido en el recorte de las emisiones, también es necesaria la colaboración de los individuos, comunidades, empresas y países. La educación y la concienciación de los ciudadanos favorecen el consumo eficiente de energía y, por tanto, la sustitución de combustibles fósiles por otros que eviten la excesiva explotación de los recursos. Por tanto, podemos afirmar que las políticas económicas 
preventivas constituyen el núcleo de medidas fundamentales para evitar el avance del calentamiento global (Whaley y Wigle, 2002).

Este documento contiene unas reflexiones amplias sobre una de las políticas preventivas más eficientes: el impuesto sobre el carbono. También analizamos su eficiencia en comparación con otros instrumentos económicos que se aplican a la reducción de emisiones.

\section{Las políticas económicas preventivas}

Las políticas económicas preventivas destinadas a paliar el calentamiento global tienen dos objetivos prioritarios: reducir las emisiones de los gases invernadero que hoy en día más daño están causando (CO2 y CFCs) y crear sumideros.

La opción de adoptar una acción preventiva depende de cómo sea la relación entre los costes de reducir las emisiones de gases invernadero y los daños que estos gases pueden ocasionar si no son sometidos a ningún control. La creación de sumideros constituye una de las medidas prioritarias. La pérdida de los bosques naturales del mundo contribuye más a las emisiones globales anuales que el propio sector del transporte. Toda reducción en la despoblación forestal es un método altamente rentable de reducir las emisiones de carbono. Los mecanismos fundamentales para conseguir dichos objetivos son: incrementar la eficiencia energética, disminuir la producción y consumo de combustibles fósiles, sustituir los combustibles fósiles por otros menos contaminantes, fomentar el cambio tecnológico y acelerar la reforestación como sumidero primordial. Dichos mecanismos pueden fomentarse a través de diversos instrumentos económicos tales como los impuestos sobre el carbono, la creación de mercados de derechos de emisiones, la eliminación de subsidios sobre combustibles fósiles, los programas de reforestación y de información pública sobre la eficiencia energética, etc.

Los instrumentos económicos más eficientes son aquellos que introducen diferentes incentivos para poder conseguir niveles de emisiones más reducidos, alterando, para ello, el sistema de precios. Por ello, también se les conoce como incentivos económicos o de mercado. El objetivo consiste en alterar el sistema de precios para disminuir o modificar las actividades económicas que puedan resultar nocivas para el medio natural. No obstante, todavía son las regulaciones administrativas las medidas que constituyen la mayor parte de las medidas de protección del medio ambiente. Estas no son expresamente incentivos económicos y, por tanto, no suelen alterar el sistema de precios. En general, son más costosas y menos eficientes que los incentivos ${ }^{1}$.

1 Una revisión de la teoría sobre los incentivos económicos puede encontrarse en García, C (2008). 
Así pues, la respuesta prudente al cambio climático radica en una combinación de políticas económicas de tipo preventivo que consigan mejoras en la eficiencia energética. Dicha prevención constituye una alternativa eficiente para adaptarse al cambio climático incurriendo en menores riesgos y propiciando el desarrollo sostenible.

Por otro lado, hay que tener en cuenta que la adopción de medidas preventivas no sólo está justificada por el riesgo que se evita, sino que también es necesario que estas tengan un punto de partida efectivo. La adopción de medidas graduales es importante, ya que de otro modo podríamos incurrir en costes prematuros (de transición o ajuste) excesivamente altos o innecesarios. Así pues, las políticas deben ser efectivas desde su puesta en marcha a la vez que adaptables a las necesidades del momento. Por ejemplo, si establecemos un impuesto sobre el carbono, este no debe partir de una tasa excesivamente alta, ya que no dejaríamos tiempo para que los mercados y los equipos se adaptaran a los nuevos cambios de los precios -o tendrían que hacerlo incurriendo en un coste excesivo ${ }^{2}$-. Pero tampoco es conveniente mantener la misma tasa a largo plazo, ya que, factores como el aumento de la población y, en consecuencia, la mayor demanda de energía pueden requerir tasas impositivas mayores con el fin de evitar emisiones más cuantiosas (Barret, 1991).

También puede ocurrir que el desarrollo y puesta en marcha de nuevas tecnologías energéticas eficientes sea más rápido de lo previsto, por lo que ello facilitaría la reducción del impuesto. La disponibilidad de nuevas tecnologías que no emitan carbono es un prerrequisito, aunque no una garantía, para reducir las emisiones de carbono a un coste razonable. El recorte de las emisiones depende también de que se reduzcan las barreras que existen en la actualidad para la difusión y transferencia de tecnología, de la movilización de recursos financieros, del apoyo a los países en desarrollo, etc. Además, la combinación óptima de políticas puede variar de un país a otro, dependiendo de factores como la estructura de los mercados de energía, de la configuración política, de la receptividad de la sociedad, etc.

Por último, cuando hablamos del coste de los instrumentos económicos solemos referirnos al coste económico medido en términos de pérdida de producción o bienestar producidos por las restricciones que estos instrumentos conllevan. De otra manera sería imposible llevar a cabo una reducción de emisiones. Pero además, existen otro tipo de costes que son los que genera la propia gestión y control del instrumento. Cada instrumento económico requiere un control y un seguimiento diferente, ya que para que cumplan bien su cometido tienen que estar bien diseñados y gestionados. Por todo esto, y, debido a que el control es costoso ( $y$, a veces imposible) este es un aspecto a tener en cuenta para elegir entre un instrumento $u$ otro.

\section{El instrumento más adecuado}

2 La segunda parte de este documento analiza todo lo referente al impuesto sobre el carbono. 
En el epígrafe anterior hemos justificado el uso de instrumentos económicos en las políticas ambientales puesto que permiten conseguir el objetivo ambiental a mínimo coste (eficiencia estática) e introducen incentivos para una mejora ambiental continua (eficiencia dinámica) ${ }^{3}$. Teniendo en cuenta que esto es cierto para cualquier problema ambiental en el que exista un gran número de contaminadores de distinta índole y procedencia, en el caso del cambio climático es todavía más importante. Esto es debido, en primer lugar, a que hay muchos contaminadores heterogéneos (prácticamente todos los agentes económicos contaminan), procedentes de distintos sectores económicos que generan emisiones dispares, muchas relacionadas con la obsolescencia tecnológica. En segundo lugar, porque los costes asociados a la reducción de emisiones son potencialmente tan elevados que es esencial intentar conseguir las ganancias de eficiencia estática y dinámica.

El problema del coste ha sido y sigue siendo una de las cuestiones cruciales a la hora de utilizar los instrumentos económicos en el ámbito del cambio climático. No deja de ser lógico que los economistas tratemos de encontrar alternativas eficientes que no sólo prevengan y actúen sobre el control de las emisiones, sino que además estos controles no resulten excesivamente caros. Es por ello que el objetivo primordial de cualquier política destinada a paliar los efectos nocivos de la contaminación ambiental (en concreto la atmosférica) es que ésta sea coste-eficiente, esto es, que pueda obtenerse la reducción máxima de emisiones para un nivel dado de gasto.

Ser rápidos y exigentes a la hora de aplicar medidas preventivas puede suponer encarecer los costes de las mismas, de ahí que sea importante considerar otro tipo de variables. Por tanto, decidir sobre si es necesaria la acción preventiva depende de cómo sea la relación entre los costes de evitar las emisiones de gases invernadero y los daños que estos gases pueden ocasionar si continúan sin ser sometidos a ningún control.

En general, los economistas tendemos a afirmar que una combinación de políticas suele ser la mejor opción, ya que la utilización de un instrumento u otro va a depender de diversos factores en cada momento. En concreto, y tras haber comparado los permisos de emisiones con los impuestos sobre el carbono en diferentes contextos (García, 2008, 2009 y 2010) podemos concluir que:

1. En el corto plazo, una cuestión primordial para poder comparar impuestos sobre el carbono y permisos de emisiones desde el punto de vista de la eficiencia es la información.

${ }^{3}$ Eficiencia estática. Este criterio hace referencia al coste de lograr una mejora ambiental determinada mediante la aplicación de un instrumento específico. Cuanto más bajo sea el coste, más atractivo será el instrumento. Eficiencia dinámica. Este criterio se refiere a la adecuación que tiene un instrumento para resolver cambios no previstos y para crear incentivos que conduzcan al desarrollo de nuevas y mejores soluciones técnicas capaces de solventar los problemas ambientales. 
2. Si los agentes económicos tienen información (gráfico 1) sobre el coste del instrumento destinado a reducir las emisiones y sobre los costes sociales que estas generan (daños ambientales), entonces ambos instrumentos podrían lograr la misma reducción de la contaminación y al mismo coste (el mercado, al tener información sobre los costes, ofrecerá un precio uniforme):

\section{Grafico 1: Los costes de reducción de emisiones con información perfecta}

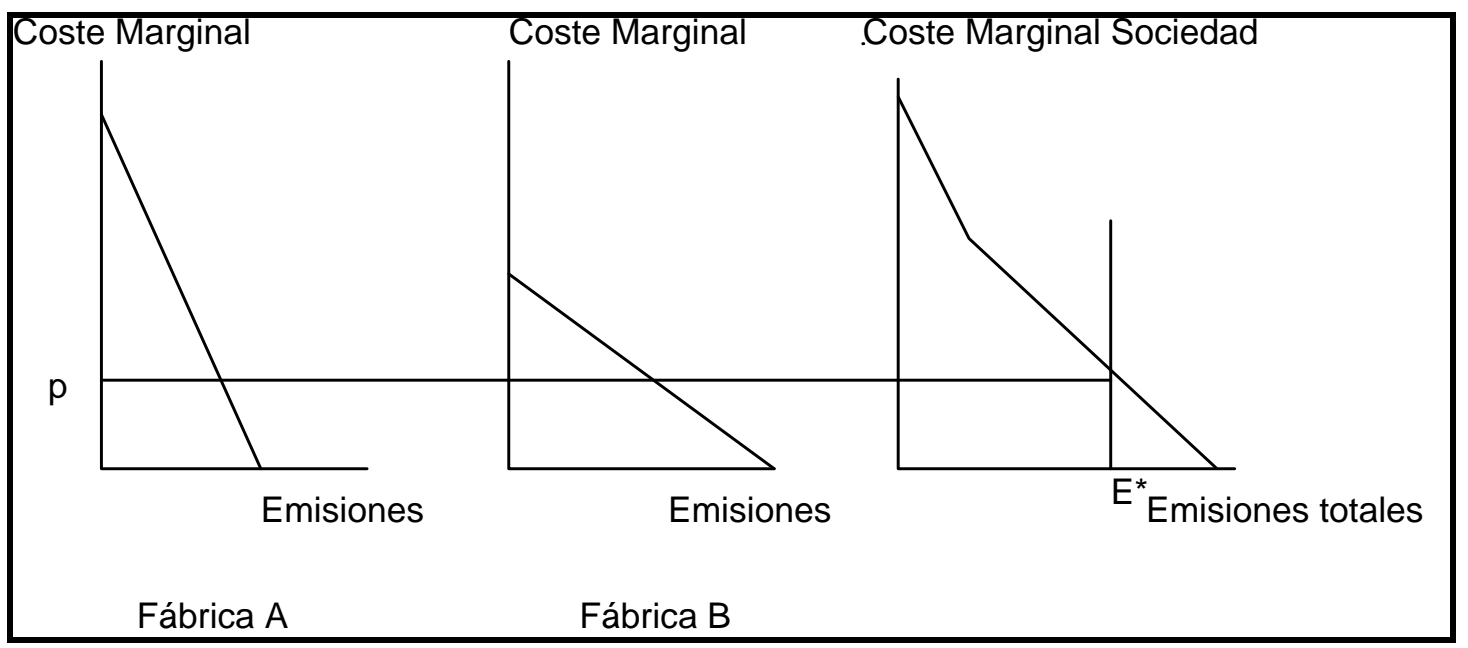

Fuente: elaboración propia. El gráfico muestra los costes de reducir las emisiones de carbono en las dos fábricas. Las emisiones se miden a lo largo del eje de accisas. Las curvas de costes marginales muestran el coste de reducir las emisiones en una unidad. Las curvas son decrecientes indicando que grandes reducciones de emisiones aumentan el coste de reducir una tonelada adicional del contaminante.

Podemos observar en el gráfico dos posibles formas eficientes de gravar las emisiones. Una de las vías sería gravar las emisiones a una tasa de $p$ unidades monetarias (euros, dólares, etc.) por tonelada de carbono. Cada fábrica reduciría sus emisiones hasta que el coste marginal igualara el impuesto. Con un sistema de permisos comercializables también se alcanza una meta de emisiones que cumple las condiciones de eficiencia. Pero además, si el mercado funciona correctamente, el precio de equilibrio de los permisos sería $p$, es decir, el impuesto ambiental óptimo.

3. En cambio, cuando la información no es perfecta (caso habitual) los agentes económicos desconocen los costes marginales de las distintas fuentes de contaminación (gráfico 2). Aquí, no esperamos que el mercado ofrezca un precio uniforme. En este caso, no ofrece igual resultado gravar las emisiones con un impuesto que establecer un sistema de permisos. Dicha elección dependerá, fundamentalmente, de las elasticidades de la curva de coste marginal de reducir las emisiones (MC) y de la curva de daño marginal (MD). En general: 
- En aquellas situaciones en las que un pequeño aumento de las emisiones puede ocasionar daños muy serios en el medioambiente, deberíamos optar por el sistema de permisos (casos en los que existen razones para pensar que MD tiene mucha pendiente, es muy sensible a las emisiones, mientras que MC es muy plana, el coste es poco sensible a las emisiones).

- Si el daño ambiental no es tan sensible a las emisiones anuales si no a la concentración de estas, entonces será preferible el impuesto (cuando el daño ambiental ha sido causado por las emisiones acumuladas).

Tanto los costes de los instrumentos preventivos como los daños que producen las emisiones pueden representarse de forma analítica. Podemos representar gráficamente, las curvas de coste marginal y las curvas de daño marginal respecto a distintos niveles de emisiones (eje de accisas).

Grafico 2. Con información imperfecta. Los costes dependen de las elasticidades de las curvas de coste marginal (MC) y daño marginal (MD)

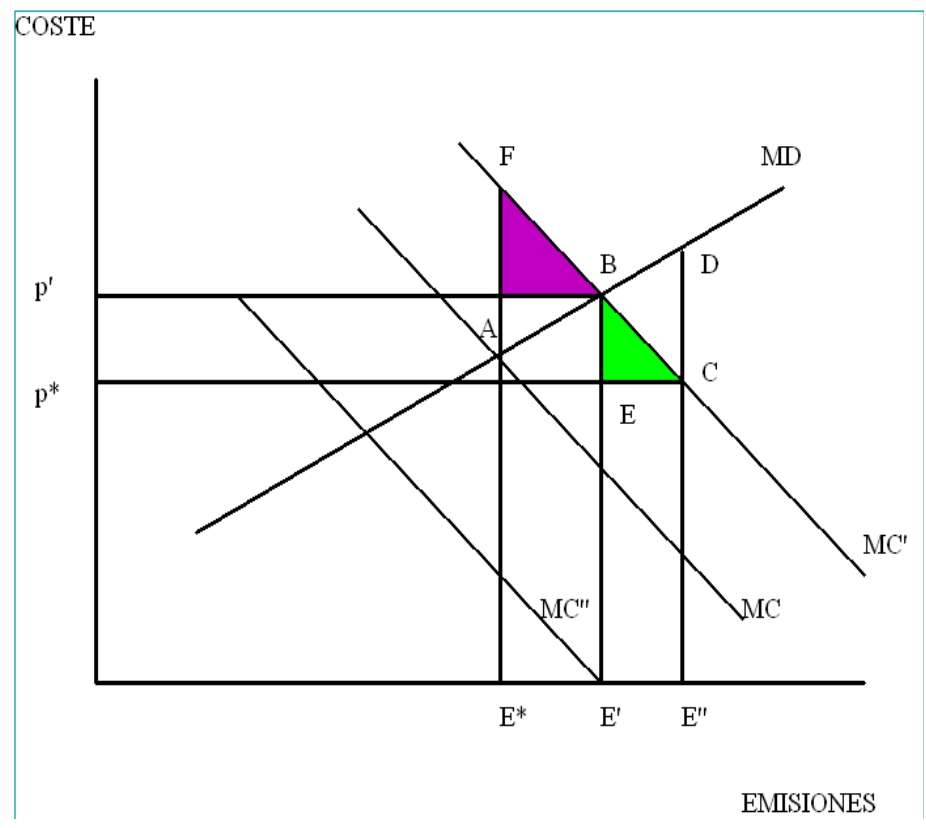

Fuente: Elaboración propia. El gráfico muestra la estructura de costes de la fábrica: la curva de coste marginal estimada aunque incierta (MC) y las curvas de costes marginales conocidas relativamente, es decir, puede ser $M C^{\prime}, o$ MC". La curva estimada es la media de las anteriores. Por otro lado, suponemos que el planificador conoce la curva de daño marginal (MD) sin incertidumbre. Basándonos en esta información el planificador encontrará que el nivel óptimo de emisiones será $E^{*}$, ya que a ese nivel el coste marginal de reducir las emisiones es igual al coste marginal del daño ocasionado. Por lo tanto, la reducción total de emisiones esperada y el coste del daño ocasionado son mínimos a ese nivel. 
En el gráfico 2 podemos ver cómo el tamaño de las áreas (sombreadas) que representan los costes netos de los instrumentos utilizados, impuestos (BCE) 0 permisos (ABF) dependen de las elasticidades de las curvas MC y MD.

Por último, a largo plazo, los aspectos más importantes a la hora de elegir entre la política más adecuada son los incentivos para desarrollar nuevas y más eficientes tecnologías y el ahorro de costes que éstas generan. Por lo general, un impuesto sobre las emisiones ofrece incentivos más fuertes para desarrollar y aplicar nuevas y más limpias tecnologías que una política basada en el control cuantitativo de las mismas. Diremos, por tanto, que su eficiencia dinámica es mayor (ver epígrafe "costes y beneficios, el caso de la eficiencia dinámica). Además, el impuesto es capaz de conseguir un recorte neto de las emisiones de carbono, ya que las empresas, con el fin de reducir la cuantía del impuesto, tendrán un incentivo adicional para reducir sus emisiones.

Por su parte, el sistema de permisos de emisiones ofrece un resultado que depende de la asignación inicial de los permisos (que tiene consecuencias en cuanto a su distribución) y de las variaciones del precio (los permisos establecen un precio por unidad o tonelada de carbono), (Paltsev, el al, 2005). Esto es relevante ya que la fluctuación del precio del carbono hace difícil estimar el coste total que conllevarían los permisos de emisión. En general, los permisos comercializables generan menores incentivos para el desarrollo tecnológico que los impuestos, pero mayores que los sistemas de regulación pura.

\section{El impuesto sobre el carbono. Reflexiones}

En esta parte consideramos tres cuestiones respecto al diseño del impuesto: la base, el tipo impositivo y los aspectos distributivos. También haremos una breve referencia al comercio.

La finalidad es ir delimitando cómo sería un impuesto que cumpliera, en la medida de lo posible las condiciones de optimalidad (ver Pigou 1938), o al menos, en la práctica, que consiguiera internalizar las externalidades producidas por las emisiones sin incurrir en excesivos costes administrativos. No consideraremos las cuestiones políticas tales como las concesiones que serían necesarias para el establecimiento del impuesto por consenso o bajo algún tipo de acuerdo.

\section{Definición}

La definición más clara de un impuesto sobre el carbono es la que realiza James Poterba (1991): "Un impuesto específico, esto es, una cantidad absoluta fija por tonelada de carbón o barril de petróleo. El impuesto está diseñado para internalizar las externalidades asociadas con el consumo de combustibles, por lo que no debería de variar ante shocks en los precios de los combustibles como lo haría un impuesto ad valorem". 
El World Resources Institute (WRI), define el impuesto sobre el carbono como "un impuesto sobre los productores de combustibles fósiles (a veces también llamado energía primaria) basado en el contenido relativo de carbono de los combustibles". Los impuestos sobre el carbono son proporcionales a las emisiones de $\mathrm{CO}_{2}$ cuando el combustible se quema. Un impuesto sobre el carbono crea un incentivo para productores y consumidores: evitar pagar el impuesto reduciendo el uso de los combustibles intensivos en carbono. Contrariamente a otros productos y actividades gravadas, esta evasión del impuesto genera importantes beneficios sociales: reducción de la utilización de energía y recorte de las emisiones de $\mathrm{CO}_{2}$.

Estos razonamientos han llevado a una variedad de propuestas basadas en la idea del "Impuesto sobre el Carbono". La idea general es que el combustible debería gravarse sobre la base de la cantidad de carbono que contiene. La cantidad de carbono del combustible, unido a la cantidad de este que es utilizada, determina cuanto dióxido de carbono será emitido a la atmósfera. Los combustibles que contienen carbono difieren en el contenido de este: el carbón es el combustible que más carbono contiene, seguido del petróleo y el gas natural. Según esto, el carbón debería gravarse más fuertemente que el petróleo y este, a su vez, más que el gas natural. Los combustibles que no contienen carbono, como la energía nuclear y las fuentes de energía renovables escaparían al impuesto y constituirían opciones relativamente más atractivas económicamente.

\section{Reforma Fiscal medioambiental}

Un impuesto sobre el carbono bien diseñado puede crear beneficios medioambientales y económicos importantes. Una estrategia encaminada a establecer un impuesto doméstico sobre el carbono que sea efectivo y que capture los beneficios antes descritos debe cumplir tres requisitos generales (WRI, 1995) ${ }^{4}$ :

1- Minimizar las pérdidas económicas que surgen a corto plazo mediante el uso eficiente de los ingresos recaudados.

2- Maximizar los rendimientos económicos mediante la reducción de otros impuestos.

3- Compensar a los grupos afectados negativamente.

Esto es lo que hoy en día se llama Reforma Fiscal Medioambiental. Esta reforma utiliza a la imposición y otros instrumentos fiscales para captar ingresos a la vez que se beneficia al medioambiente. Para los países desarrollados los impuestos sobre el carbono pueden sustituir a otros impuestos, tales como los impuestos sobre la renta además de mejorar las condiciones económicas reduciendo la tasa de desempleo ${ }^{5}$. En los países en

\footnotetext{
4 World Resurces Institute. (1995).

5 La cuestión de la afectación en el empleo varía según los estudios. En el anexo 1 de este documento se muestran resultados donde el empleo se reduce al introducir el impuesto.
} 
desarrollo, los ingresos de los impuestos sobre el carbono pueden destinarse a medidas encaminadas a paliar la pobreza tales como el desarrollo de infraestructuras $o$ los incentivos para una industria más eficiente energéticamente. La reforma fiscal ambiental nos brinda una oportunidad para desarrollar estrategias impositivas que mitiguen el cambio climático a la vez que impulsan el crecimiento económico y el desarrollo.

\section{Costes y beneficios}

Comparado con un sistema de permisos de emisiones, el impuesto sobre el carbono tiene menor complejidad para los gobiernos y ofrece mayor certidumbre respecto a su coste para los contaminadores. Los gobiernos gravarán a las empresas contaminantes por cada tonelada de CO2 emitida a la atmósfera. Por tanto, el contaminador tiene un motivo para reducir las emisiones de $\mathrm{CO} 2$, que no es más que evitar el impuesto y, por tanto, puede aproximar sus costes a sus beneficios con mayor certidumbre. El impuesto es menos complejo para los gobiernos debido a que muchos países gravan desde hace tiempo a los vehículos en base a sus niveles de emisiones, lo que hace que el impuesto sobre el carbono sea un complemento de otros impuestos previamente existentes (aunque determinar el contenido de carbono no sea tan sencillo en algunas ocasiones). Esto, unido a los ingresos que se derivan del impuesto constituye importantes ventajas. Las desventajas del impuesto son, sin duda, su impopularidad entre la clase política y los sectores más afectados y, la incertidumbre acerca de su efectividad en la reducción de emisiones.

Por otro lado, cualquier impuesto lleva asociado un nivel de reducción de la contaminación y, asociado a cualquier nivel de reducción de la contaminación habrá un coste, el coste de lograr la reducción marginal. No conocer el impuesto apropiado es lo mismo que no conocer el nivel apropiado de reducción de la contaminación. Hasta la fecha, se han realizado numerosas propuestas para lograr distintos niveles en la disminución de las emisiones.

El problema a la hora de establecer una meta determinada de emisiones surge cuando hay que elegir la meta efectiva. Si, por ejemplo, establecemos una meta de reducción de emisiones podemos estar seguros acerca del nivel de emisiones pero no del coste asociado. Sin embargo, si nuestro objetivo es establecer un impuesto y no un límite cuantitativo de emisiones, podemos conocer cuanto costará reducir las emisiones en el margen, esto es, el coste marginal del impuesto - los que contaminan no gastarán más de lo que ahorrarían si no pagaran el impuesto- pero no el nivel de emisiones asociado a dicho impuesto.

Una razón para preferir el impuesto sobre el carbono es que la reducción de las emisiones dependerá no sólo de la magnitud del impuesto, sino también del precio de los combustibles fósiles, y este precio es variable. Por ejemplo, si el precio del crudo permanece alto, es posible que muchos países logren las metas de reducción de emisiones mencionadas anteriormente sin incurrir en costes adicionales, es decir, sin gastar dinero para evitar los daños potenciales del cambio climático (existen estudios que muestran la correlación existente 
entre el aumento del precio del crudo y la reducción de emisiones) ${ }^{6}$. Por otro lado, si los precios del crudo disminuyen hasta su niveles previos, el coste de llevar a cabo una meta cuantitativa podría volverse muy alto. Si imponemos un impuesto, podemos estar seguros de que siempre tendremos un incentivo para reducir las emisiones. Esta es una de las grandes virtudes del impuesto sobre el carbono.

Pero quizás la mayor ventaja que ofrece este tipo de impuesto es su eficiencia dinámica. A largo plazo, los aspectos más importantes a la hora de elegir entre la política más adecuada son los incentivos que se originen para desarrollar nuevas y mejores tecnologías y su influencia sobre el desarrollo económico. Un breve análisis de la misma nos llevará a entender los beneficios del impuesto frente a otros instrumentos. Veamos un ejemplo.

\section{Gráfico 3. Reducción de costes mediante la eficiencia dinámica (ahorro de costes mediante la introducción del impuesto)}
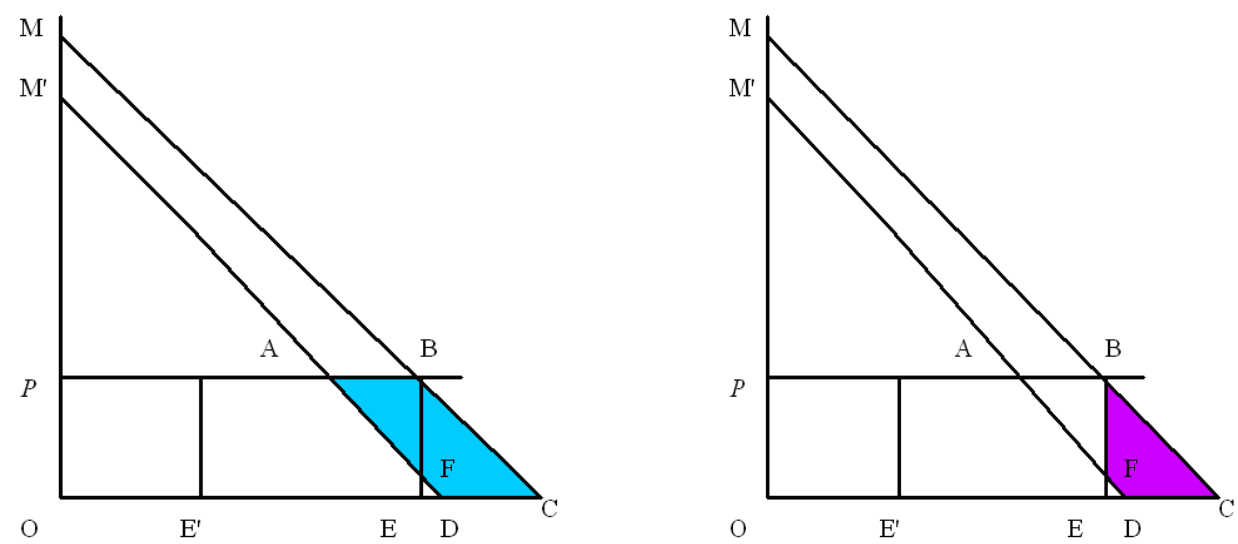

\section{Ahorro de costes con impuesto sobre el carbono Ahorro de costes con regulación}

Fuente: elaboración propia. Ahorro de costes con un impuesto sobre el carbono. El gráfico muestra cómo con un sistema de regulación puro el ahorro de coste por la adopción de una nueva tecnología sería el área DCBF. En cambio, con un impuesto, el ahorro de costes es mayor (área $A B C D$ ).

Consideremos una planta de producción que emite un gas contaminante a la atmósfera (dióxido de carbono, por ejemplo). La curva de coste marginal de reducir las emisiones de carbono es la que viene delimitada por los puntos de corte MC. Supongamos que la política ambiental consiste en un sistema de control estricto de la cantidad de emisiones (regulación), esto es, el gobierno o planificador impone un límite de emisiones (E toneladas) cada año. El coste

6 Metcalf y Weisbach, 2009 
total de esta política es igual al área por debajo de la curva $\mathrm{MC}$, es decir, EBC. Supongamos ahora que la planta puede desarrollar una nueva tecnología que reduciría los costes de la política reguladora y que la nueva curva de coste marginal es M'D. Si se adopta el coste total sería ahora el triángulo EDF. El ahorro que ha generado la nueva tecnología es igual al área DCBF. Es estrictamente igual a la reducción del coste de la política aplicada.

La situación es distinta cuando la política ambiental es un impuesto que grava las emisiones de carbono. Supongamos que el impuesto es p. Aquí el coste total para la planta con la tecnología antigua es ECB (coste de la política reguladora de emisiones) más OEBp (pago del impuesto). El ahorro de costes que produce la nueva tecnología es ahora DCBA. Este es estrictamente mayor que el ahorro de costes producido bajo la política de control (regulación). Debido a que la planta no podrá únicamente reducir su coste mediante el uso de la nueva tecnología tendrá también que reducir el pago del impuesto mediante la reducción de las emisiones. Por tanto, parece que, al menos teóricamente, un impuesto sobre las emisiones ofrece incentivos más fuertes para desarrollar y aplicar nuevas y más limpias tecnologías que una política basada en el control cuantitativo de las emisiones, además de conseguir un recorte neto de las mismas (Farrow, 2001).

Sólo nos quedaría analizar que ocurriría bajo un sistema de permisos comercializables. ¿Ofrecería el mismo resultado que la política de regulación 0 la del impuesto? La respuesta es, depende. Si el precio de los permisos no cambia debido a la introducción de la nueva tecnología, el resultado será exactamente el mismo que el del impuesto. No obstante, si varias empresas adoptan nuevas tecnologías, la demanda total de permisos caerá y también lo hará el precio. Este hecho hará que disminuya la rentabilidad de haber adoptado la nueva tecnología y con ella los incentivos para desarrollar nuevos métodos de producción. En definitiva y en general los permisos comercializables ofrecerán menores incentivos para el desarrollo tecnológico que los impuestos, pero mayores que los sistemas de regulación pura.

Por todo ello, podemos decir que el coste total de reducir las emisiones puede ser menor caso de aplicarse una política impositiva sobre el carbono, ya que, dado que cada productor que utilice combustibles fósiles pagará el mismo impuesto, cada uno de ellos tendrá por tanto el mismo incentivo para reducir las emisiones. Ahora bien, lo mismo no puede ser aplicado a otras políticas. Por ejemplo, si se aplicara un impuesto sobre el petróleo (un solo tipo de combustible fósil), los propietarios de los vehículos tendrían un mayor incentivo para reducir las emisiones que otros contaminadores, por lo que el coste de hacer frente a las reducciones de emisiones resultantes sería excesivo. En definitiva, con el impuesto sobre el carbono siempre podrían redistribuirse a los grupos más pobres las ventajas de eficiencia que supone dicho impuesto, esto es, la diferencia entre los costes de lograr un cierto nivel de reducción de emisiones con el impuesto sobre el carbono y los costes que supondría una política alternativa. 


\section{La base del impuesto}

Para resolver esta cuestión debemos considerar primero el problema de decidir cuanto debe variar el impuesto según el combustible. Como ya hemos dicho, para que el impuesto sea eficiente este debe establecerse sobre el contenido de carbono 7 - emisiones de carbono o las de $\mathrm{CO}_{2-}$, y no sobre el uso de los combustibles fósiles. También sabemos que las emisiones varían según el tipo de combustible. El carbón contamina más que el petróleo y este último más que el gas. Por lo tanto, el impuesto más alto debe imponerse sobre el carbón y el menor sobre el gas. Las fuentes de energía no fósiles, tales como la hidroeléctrica y la nuclear entre otras, no emiten $\mathrm{CO}_{2}$, por lo que no estarían sujetas a este tipo de impuesto. No obstante, estas formas de energía tienen sus propios costes medioambientales, por lo que, como regla general económicamente eficiente, todos los precios deberían reflejar los costes medioambientales y algunos sociales.

Una cuestión más difícil concierne a la magnitud absoluta del impuesto. ¿Qué tamaño debería tener este impuesto? La respuesta depende de que el impuesto sea el objetivo a alcanzar o no. Si el impuesto es el objetivo de una política determinada, entonces habría que preguntarse: ¿ en cuánto deberían reducirse las emisiones?. La respuesta no es fácil. Una opción sería establecer un impuesto sobre el carbono y observar la reducción de emisiones resultante, en vez de establecer una meta determinada de emisiones e intentar calcular el impuesto que sería necesario para alcanzar dicha meta, tarea que no es fácil, aunque sea el método más comúnmente utilizado.

Volviendo a la pregunta que nos planteábamos al principio sobre qué tamaño debe tener el impuesto debemos hacer algunas aclaraciones adicionales. Si el impuesto está enfocado únicamente a consideraciones medioambientales, la tasa impositiva ideal sería aquella bajo la cual los beneficios resultantes de la reducción de la última tonelada de carbono (beneficios marginales) igualaran el coste adicional resultante de la eliminación de esa tonelada (coste marginal). Como ya hemos apuntado, la teoría muchas veces no tiene correspondencia con la práctica. Lo que queremos resaltar es que ese punto de equilibrio es muy difícil de alcanzar, especialmente tratándose de beneficios que pueden manifestarse a lo largo de muchas generaciones futuras o de situaciones en las que la ciencia o los riesgos relativos no están lo suficientemente comprendidos.

En realidad, el impuesto o la política eficiente no podría calcularse realmente hasta que las emisiones fueran traducidas a concentraciones atmosféricas, ya que son las concentraciones y no el nivel de emisiones las que determinan el calentamiento de la Tierra. Tampoco podría ser calculado hasta que sean estimados los efectos de las concentraciones crecientes, esto es, el ritmo y nivel de calentamiento global; hasta que los daños ambientales y económicos

7 Dado que los pesos atómicos del carbono y el oxígeno son 12 y 16 respectivamente, una tonelada de carbono equivale a 3,67 toneladas de dióxido de carbono. 
asociados al aumento de la temperatura sean estimados y hasta que se valoren los daños ocasionados.

No obstante, la ausencia general de datos formales sobre impactos medioambientales no impide que se desarrollen programas destinados a reducir los riesgos. Los impuestos medioambientales, cuya aplicación es cada vez más amplia en gran número de países, constituyen un tipo de política preventiva muy importante y su justificación radica en que son una vía para incrementar el precio de ciertos bienes, para así reflejar los costes sociales asociados con el consumo de estos.

De todas formas, el método alternativo más común para determinar el tamaño del impuesto sobre el carbono es, como ya hemos apuntado, estimar el nivel impositivo necesario para conseguir una determinada reducción de emisiones. Es difícil establecer el impuesto "correcto" con antelación y además, depende del período de tiempo seleccionado y del grado de control requerido. Por ejemplo, el impuesto necesario para estabilizar las emisiones a un nivel en el año 2015 puede ser diferente del impuesto que estabilice las emisiones en otro año (2025). La mayor parte de los análisis económicos sobre las reducciones de emisiones de carbono sugieren que los primeros recortes de emisiones (los primeros 15 o 20 años) pueden lograrse prácticamente sin costes -impuestos reducidos-. Pero, a medida que pasa el tiempo, mantener esas reducciones 0 incluso aumentarlas puede ser cada vez más complicado, por lo que sería necesario un impuesto mayor. No obstante, a medida que pasa el tiempo irán surgiendo alternativas eficientes a los combustibles fósiles, como energías renovables y tecnologías limpias, lo cual tenderá a reducir el impuesto requerido.

Por otro lado, cuando hablamos de la base del impuesto estamos intentando determinar qué es lo que debería ser gravado por el mismo. En ese proceso debemos tener en cuenta los costes marginales de reducir las emisiones (en cuanto se reducirían las emisiones si un euro adicional se gastara en ese cometido). El motivo es que para minimizar el coste total de reducir las emisiones la base del impuesto debe incluir actividades que tengan un bajo coste marginal de reducir emisiones aunque su contribución total a la generación de emisiones sea pequeña. Por ejemplo, si es relativamente fácil reducir las emisiones de metano procedentes de los vertederos puede ser importante incluirlos en la base del impuesto, a pesar de que su contribución a las emisiones no sea muy alta. Lo mismo sería atribuible a otras actividades no relacionadas con los combustibles fósiles (Reilly, et al, 2003).

Por tanto, a la hora de establecer la base del impuesto "óptimo" y teniendo en cuenta la teoría existente al respecto, tendremos que comparar el ahorro de costes administrativos que produce tener una base pequeña con los beneficios en eficiencia que obtendríamos con una base más amplia. La base se 
establecería de tal forma que el beneficio de una leve ampliación de la base igualara el aumento en los costes administrativos de su ampliación8.

Y hasta aquí la teoría. El análisis de la realidad nos lleva a tener en cuenta otro tipo de consideraciones, tales como la complejidad de intereses políticos que levantaría la ampliación de la base impositiva. Muchos se opondrían a ella. No obstante, la ventaja es que una base más amplia daría lugar a una tasa impositiva más baja en el largo plazo, relajando la oposición frontal al impuesto.

En general, los pocos impuestos sobre el carbono existentes en la actualidad tienen una base más bien estrecha (cinco países escandinavos y Reino Unido). Aunque los primeros impuestos datan de 1991 (Noruega) tampoco tienen una tasa uniforme para las fuentes de emisiones que gravan. Además de no estar armonizadas tampoco son impuestos muy efectivos debido a las numerosas exenciones que tienen. El Reino Unido impuso un impuesto sobre el clima en 2001. La tasa incide en el uso de energía procedente del sector industrial y comercial, quedando exentos el consumo doméstico y el transporte. El tipo impositivo que utiliza es reducido ${ }^{9}$.

En cuanto al sistema de permisos de emisiones europeo hay que decir que su base no es amplia y que cubre una parte relativamente pequeña de emisiones de gases invernadero. Según Convery et al (2007), la comisión Europea estimó en 2010 que menos de la mitad de las emisiones de CO2 y menos de 1/3 de las emisiones procedentes de otros GEl estaban cubiertos por el sistema europeo de permisos de emisiones. Por ejemplo, el sector de transporte está excluido, aunque la excusa para hacerlo fuera que ya existían impuestos que gravaban la gasolina y otros combustibles de uso automovilístico.

\section{El tipo impositivo}

Un análisis equivalente al que ofrecíamos en el gráfico 2 es el siguiente:

8 Ver Metcalf et al (2009). Ofrecen un análisis teórico riguroso respecto a los costes y beneficos de ampliar la base del impuesto sobre el carbono.

$9 \mathrm{El}$ anexo 2 muestra los impuestos sobre el carbono existentes. 


\section{Gráfico 4: el tipo impositivo óptimo}

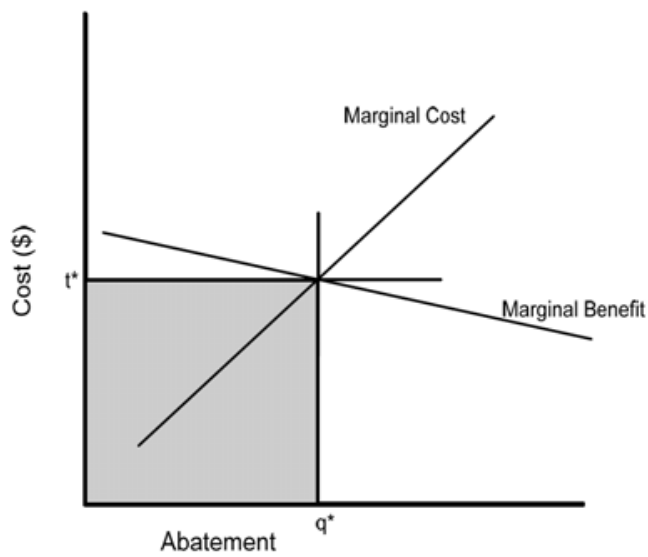

Fuente: Metcalf y Weisbach (2009).

Donde la curva de beneficio marginal es equivalente a la curva de daño marginal presentada en el gráfico 2. El coste marginal es el mismo, simplemente ahora cambia la pendiente (es positiva en vez de negativa) al representarse en relación a la reducción de emisiones y no a la cantidad de emisiones. Lo mismo le ocurre a la pendiente de la curva de beneficio marginal.

En cualquier caso, para establecer un impuesto como el representado en el gráfico 4 el gobierno necesitaría estimar el coste marginal de reducir las emisiones además de estimar también el beneficio marginal derivado de esa reducción de emisiones. Esta, como ya expusimos en la primera parte de este documento, es una tarea no fácil ya que el gobierno o la autoridad competente necesita información acerca del coste marginal y del daño marginal de reducir las emisiones 10 .

Aunque teóricamente el establecimiento de un impuesto sobre el carbono debe cumplir condiciones de eficiencia económica, en la práctica no es tan sencillo, sobre todo la dificultad que tiene el cálculo de los impactos y su traslado a daños marginales. Por ello, en la práctica, muchos analistas (Nordhaus, 2007) estiman un conjunto de impuestos, establecidos a lo largo del tiempo, que tengan la finalidad de cumplir una meta de reducción emisiones o bien que estabilicen las concentraciones totales de carbono de la atmósfera. Esta última aproximación tiene dos partes. Una primera que incluye una toma de decisiones acerca de qué nivel de concentraciones de GEI estamos dispuestos a tolerar y una segunda, más técnica, que radica en cómo hacemos para conseguir esto de la mejor forma posible. Claro está que los análisis ofrecen distintos impuestos para cada meta propuesta.

10 El IPCC, en su Working Group II revisa 100 estudios distintos sobre el impuesto óptimo, con un rango de 3 a 95 dólares, estimando una media de 12 dólares por tonelada métrica de $\mathrm{CO} 2$ para 2005. (Intergovernmental Panel on Climate Change (2007), p. 16). 


\section{Gráfico 5: Posibles trayectorias para la reducción de emisiones desde la perspectiva del coste}

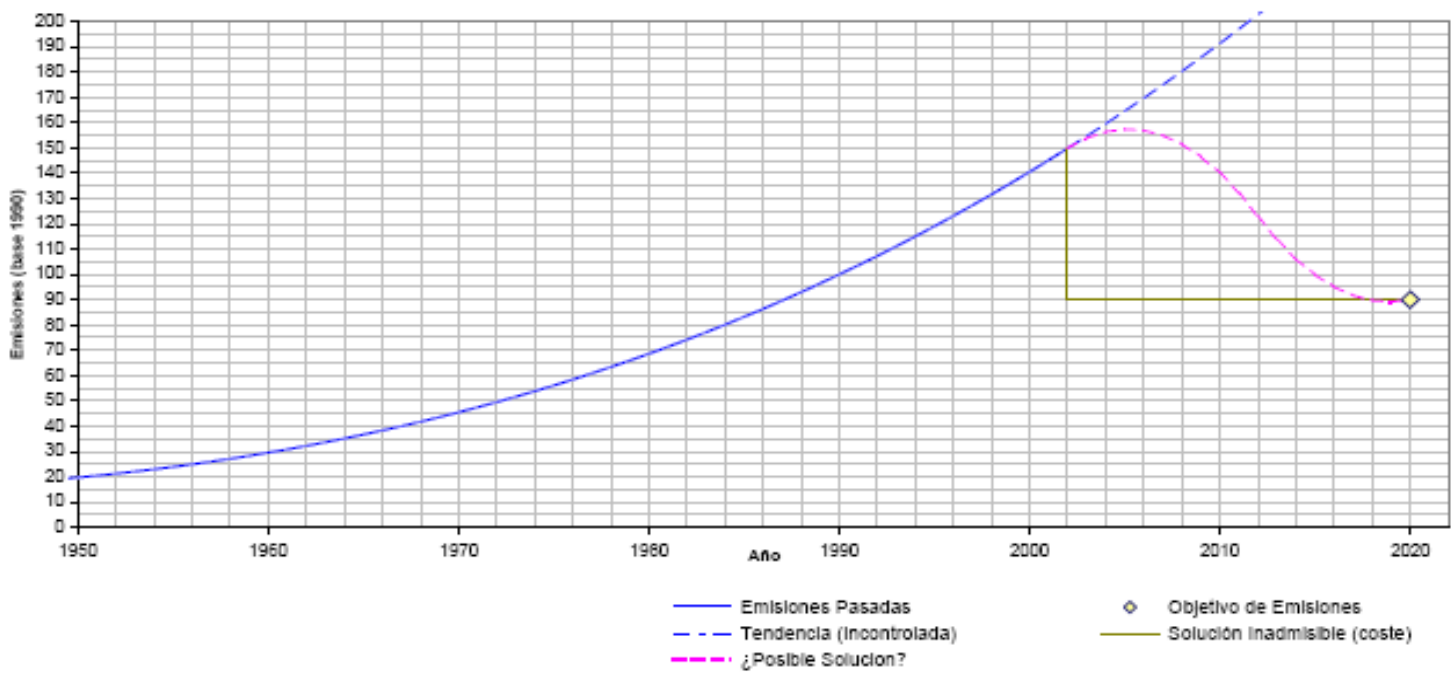

Fuente: elaboración propia

El gráfico 5 muestra una simulación sobre las posibles trayectorias que puede adoptar la reducción de las emisiones y su correspondencia con los costes que traerían consigo en los distintos casos. La cuestión primordial es que debemos aplicar instrumentos mitigadores, como el impuesto sobre el carbono, que consigan una reducción gradual de las emisiones ya que, de lo contrario, podríamos incurrir en costes excesivos, perdiendo el objetivo de eficiencia al que hemos hecho referencia. En el gráfico, la trayectoria óptima sería la que apuntamos como "posible solución" ya que conseguiríamos reducir las emisiones de forma gradual (en el año 2020) a un coste mínimo o "costeeficiencia". Un impuesto gradual podría conseguir esa trayectoria de emisiones sin incurrir en coste muy altos (ver epígrafe "el impuesto gradual").

Varios estudios recientes muestran resultados concluyentes sobre el efecto que distintas tasas impositivas pueden tener en el precio de los combustibles y en la consiguiente reducción de emisiones ${ }^{11}$. Algunos resultados de los estudios citados se pueden ver en el anexo 1 de este trabajo. En concreto, Dingell, Stara y Larson en Metcalf, G.E et al (2008) nos muestran estimaciones de distintas tasas impositivas que dan lugar a diversas trayectorias de emisiones. Claramente, tasas más ambiciosas (Larson) consiguen, a la larga, mayores reducciones de emisiones. Sin embargo, para los primeros 15 años, la aplicación de tasas impositivas distintas no consigue, en general, reducciones importantes. Asimismo, se estudia la incidencia que dichas tasas tienen sobre

11 METCALF, G. E., S. PALSTEV, J. REILLY, H. D. JACOBY, and J. HOLAK (2008): "Analysis of U.S.

Greenhouse Gas Tax Proposals," Cambridge: MIT. 
el bienestar, siendo las mayores pérdidas las relacionadas con tasas más altas. Dichos estudios también muestran los ingresos obtenidos de la aplicación de diversos impuestos sobre el carbono. Sus estimaciones sobre ingresos para 2015 de impuestos relativamente bajos oscilan entre 69 mil millones de dólares y 126 mil millones. Esto quiere decir que un impuesto de 25 dólares por tonelada métrica de CO2 aumentaría el precio de la gasolina en alrededor de 22 céntimos por galón y el precio del carbón en 2,5 céntimos por KWh. El impuesto sobre el carbono incrementaría además el precio de otras actividades que utilizan la energía como un input intermedio. El anexo 1 de este trabajo (tablas 5 y 6), muestra la incidencia que tiene un impuesto de 27 dólares por tonelada de $\mathrm{CO} 2$ equivalente tanto en los precios de los distintos combustibles como en el consumo de estos. Se observa un encarecimiento relativo del carbón y una consecuente reducción en su consumo a favor de un incremento en el consumo del gas natural y del petróleo, fruto de la mayor elasticidad cruzada entre el precio del carbón y la demanda de estos dos combustibles.

\section{El problema de la elasticidad}

Unos de los efectos más importantes que se derivan del tipo impositivo que finalmente adoptemos es la cuestión de la elasticidad. A la hora de imponer un impuesto sobre el carbono es primordial conocer su magnitud y esta depende de qué tipo impositivo sea el que adoptemos para reducir las emisiones en una cierta cantidad.

Dependiendo de cual sea el tipo impositivo se obtendrán distintos cambios porcentuales en los precios de los combustibles, lo que a su vez, dará lugar a variaciones en el consumo. El instrumento económico que relaciona las variables anteriores es la "elasticidad de la demanda respecto al precio", que es una medida de la sensibilidad del consumo ante cambios en los precios. Para saber qué cambios en los precios serán necesarios para producir una reducción particular del uso de combustibles fósiles necesitamos conocer cuál es la elasticidad de la demanda para esos combustibles, tarea que no es fácil por una serie de razones (Anderson, 1993).

En primer lugar, la elasticidad demanda-precio varía con el período de tiempo considerado. Si, digamos que disponemos de poco tiempo para reaccionar ante un aumento del precio, lo más probable es que mantengamos el mismo comportamiento, soportando, por tanto, el aumento del precio. Es necesario que pase más tiempo para que cambie el comportamiento de los consumidores, por ejemplo, para que se decidan a comprar aparatos domésticos ahorradores de energía.

En segundo lugar, los precios de los bienes afectan a la demanda no sólo de dichos bienes sino también a la de sus sustitutos. Por ejemplo, un aumento del precio del carbón puede abaratar relativamente el petróleo o el gas natural y, por lo tanto, suscitar la sustitución del carbón por estos otros combustibles. El instrumento económico que nos relaciona estas variables es la "elasticidad cruzada de la demanda". Las propuestas de un impuesto sobre el carbono implican simultáneamente a muchas elasticidades de demanda precio y a 
elasticidades cruzadas, por ejemplo: un aumento del precio del carbón afectará a la demanda de petróleo y gas natural (aumentándolas) y a la suya propia (reduciéndola); un aumento del precio del petróleo afectará a la demanda de carbón y gas natural, etc.

En tercer lugar y de gran importancia está la tecnología, esto es, que exista la posibilidad de introducir cambios tecnológicos más eficientes. Por ejemplo, un alto tipo impositivo sobre el carbono puede ser un incentivo para que una empresa sustituya su método de producción por otro menos contaminante. Pero puede ocurrir que ese nuevo método no exista cuando se impone el impuesto por primera vez, así que, prever cuál es el efecto del impuesto depende de que sea posible prever si el desarrollo tecnológico tendrá lugar o no al menos en un período no demasiado prolongado, lo que le permitiría a la empresa poder sustituir su tecnología contaminante por otra más eficiente. Obviamente, en el largo plazo este problema desaparece, ya que existirá la posibilidad de combinar la tecnología avanzada con el impuesto12.

Una cuarta cuestión es que el impuesto afectará al precio antes del impuesto, ya que los productores aceptarán alguna disminución de sus márgenes comerciales (con una posible reducción del precio de venta) antes que aceptar una caída de sus ventas. El tipo porcentual del impuesto no se traslada netamente a un incremento porcentual idéntico del precio. Si los márgenes comerciales disminuyen, entonces el incremento del precio debido al impuesto será menor que el tipo impositivo.

Si conociéramos la respuesta de la demanda ante un incremento del precio del combustible podríamos calcular la reducción de emisiones asociada a un impuesto sobre el carbono dado. Todo lo que tendríamos que hacer sería calcular los cambios en el consumo de cada combustible asociados al impuesto (carbón, petróleo y gas natural), multiplicar estos cambios por el peso relativo apropiado de las emisiones (porcentaje de emisiones correspondiente a cada combustible) y sumar los resultados de los tres combustibles. Pocos autores han hecho algún intento de calcular las elasticidades de la demanda de energía, ya que no son fáciles de estimar13. Además, no hay garantía de que las estimaciones basadas en datos históricos sirvan para predecir futuras respuestas.

12 Como ya hemos visto en un epígrafe anterior, el ahorro de costes que produce la combinación de la nueva tecnología con el impuesto (eficiencia dinámica)es mayor que con otro tipo de instrumento mitigador.

13 Barret (1991) presenta para el Reino Unido las estimaciones hipotéticas de las elasticidades de demanda de energía y las cruzadas, así como el impuesto sobre el carbono necesario para reducir las emisiones en un $20 \%$. Las elasticidades de demanda fluctuan entre $-0,5$ y -2 , mientras que las cruzadas fluctuan entre 0,1 y 0,75. Por ejemplo, una elasticidad de demanda del carbón de -0,5 significa que un incremento del 1\% en el precio del carbón reducirá la demanda de ese combustible en un $0,5 \%$. De igual modo, una elasticidad del precio cruzada entre carbón y petróleo de 0,1 significa que un incremento del 1\% en el precio del carbón aumentará la demanda de petróleo en un 0,1 por ciento. 
En realidad, las elasticidades deberían utilizarse para predecir la respuesta de la demanda ante cambios pequeños en los precios. Si sólo se tienen en cuenta estos efectos e ignoramos otros factores importantes dentro del análisis podría verse qué ocurre cuando los cambios en los precios son grandes, ya que lo que se pretende es tener una idea de la respuesta de la demanda de energía cuando se impone el impuesto bajo distintos supuestos.

\section{Equidad y distribución}

El impuesto sobre el carbono es regresivo. Para evaluar los efectos distributivos que ocasiona un impuesto sobre el carbono hay que tener en cuenta una realidad importante, y es que las personas de renta inferior suelen gastar en energía una proporción mayor de su gasto total que los grupos de renta más altos, soportando, por tanto, una mayor carga relativa del impuesto. Esto, aunque puede constituir un argumento contra el impuesto sobre el carbono se debilita por los motivos siguientes:

En primer lugar, dado que la sociedad desea hacer algo para reducir las emisiones de gases invernadero, la comparación a tener en cuenta no es el bienestar de una persona o familia con o sin el impuesto, sino con el impuesto y alguna otra política que reduzca, a su vez, las emisiones. Un impuesto sobre el carbono es regresivo, pero también lo son muchas de las alternativas disponibles para reducir las emisiones de gases invernadero. Por ejemplo, cuando se establecen estándares de eficiencia energética para vehículos, aparatos eléctricos, etc, estamos adoptanto una medida más bien regresiva, ya que los propietarios de estos aparatos, que suelen tener mayor nivel de renta, pagarán, a la larga, facturas energéticas más bajas. Sin embargo, la investigación económica muestra que la gente pobre prefiere comprar menos accesorios energéticos eficientes debido a su reducida capacidad adquisitiva, por lo que, el consumo de productos menos eficientes les producirá facturas mayores.

La segunda, es que el ingreso anual de una familia es un mal indicador de su bienestar actual. En vez de evaluar los efectos del impuesto en base a los ingresos y gastos anuales en energía de los consumidores que, efectivamente muestran la regresividad del impuesto (los pobres gastan una fracción mayor de su renta en energía), debería escogerse el gasto total en consumo como indicador de bienestar (Poterba, 1991). El motivo es que los ingresos familiares pueden variar de un año a otro, tanto por motivos predictibles como no predictibles, sin embargo, el consumo está basado en el ingreso a largo plazo. Algunos estudios realizados para Estados Unidos 14 muestran que cuando se mide el bienestar familiar en base al gasto total en consumo en vez del ingreso anual se reduce la regresividad del impuesto. Esto significa que el gasto total en consumo es un indicador más fiable para medir los efectos redistributivos

14 El autor James Poterba muestra sus resultados empíricos sobre los efectos redistributivos del impuesto sobre el carbono en referencia al ingreso anual, por un lado, y al gasto total en consumo, por el otro, en Global Warming, Economic Policy Responses, p.79. 
del impuesto. Esto se debe principalmente a que las familias experimentan cambios transitorios en su ingreso anual - por ejemplo desempleo, enfermedad, etc.- pero sus gastos reflejarán circunstancias económicas a largo plazo antes que condiciones transitorias.

En tercer lugar, el impuesto brindará una serie de ingresos ${ }^{15}$, de los que, una gran parte pueden ser redistribuidos hacia los grupos inferiores de renta. En efecto, el impuesto sobre el carbono tiene el mismo efecto que un aumento del precio de la energía en una economía que dependa íntegramente de las importaciones de energía. Pero además, el impuesto puede generar ingresos sustanciales, dinero que podría destinarse a un buen uso dentro del país. Es obvio que todos los países tienen impuestos que generan ingresos. El problema de estos impuestos es que suelen dar lugar a distorsiones importantes. Por ejemplo, un impuesto sobre la renta crea desincentivos al trabajo, un impuesto que grave las ganancias procedentes de la inversión genera un incentivo para que los consumidores sustituyan consumo futuro por consumo presente, etc. Estas distorsiones tienen un coste en términos de producto nacional y, por tanto, afectan al crecimiento de la economía16. Un impuesto sobre el carbono corrige estas distorsiones haciendo que los contaminadores paguen los costes medioambientales de sus acciones. El establecimiento de un impuesto de este tipo no sólo ayudaría a proteger el medio natural sino también incentivaría la sustitución de otras fuentes de ingresos (impuestos sobre la renta, sociedades, etc.) que dañan la economía17. Esto es lo que se conoce como "reciclaje del impuesto sobre el carbono".

Otra alternativa sería gastar parte de los ingresos que nos brinda el impuesto en invertir en una economía baja en carbono. Aquí sería necesario recurrir a otras fuentes de ingresos adicionales para reemplazar la tecnología antigua por la nueva de captura y almacenaje de carbono. Estas tecnologías, ya existentes en la actualidad aunque poco explotadas, traerán consigo mayor eficiencia energética y, por tanto, menores emisiones. La desventaja es que es que son necesarios recursos de inversión importantes.

La opción quizás que tiene más seguidores, aunque no la única, es la de mantener la neutralidad del impuesto (ingresos y efectos distributivos neutrales). De esta forma los ingresos del impuesto se destinarían a reducir

15 Ver epígrafe de la Reforma Fiscal Medioambiental.

16 Según Dower y Reppeto (1990), estas distorsiones suponen un coste de entre un 4-7 por ciento del PNB en Estados Unidos.

17 Barker y Lewney (1990) compensan una bajada del IVA con los ingresos obtenidos del impuesto sobre el carbono. Además, también observan que el impuesto no tiene efectos negativos notables sobre el crecimiento. Puesto que el impuesto que ellos establecen es bastante alto, de aquí se deduce que las ganancias de eficiencia derivadas de la reducción del IVA también deben ser grandes. 
otros impuestos manteniendo la progresividad (el impuesto sobre el carbono no cambia la progresividad del sistema impositivo) ${ }^{18}$.

\section{Un impuesto gradual}

Un aspecto fundamental acerca del impuesto sobre el carbono es sobre si se introduce de forma gradual a lo largo del tiempo y así se va aumentando su tasa, e incluso su base, o si se introduce una tasa alta desde el primer momento, sin dar opción a un período transitorio de adaptación. Otra opción barajada es que, en una primera fase, las emisiones (hasta un límite determinado) queden exentas del impuesto, por ejemplo, un nivel de emisiones que iguale a las de un año de referencia. La introducción de una tasa elevada desde el primer momento tiene la doble desventaja de los costes administrativos y de reducción de emisiones que acarrea y de la dificultad de que sea políticamente factible. No obstante, algunos estudios defienden esta aproximación (ver Metcalf, et al, 2008). El motivo de su defensa es que maximizaría el llamado "efecto de anticipación". Si las empresas entienden y tienen en cuenta que el impuesto se introducirá sin ningún tipo de consideración transitoria para adaptar las inversiones al nuevo sistema, entonces empezarán adaptándose y ajustando sus decisiones desde el primer momento, anticipándose a los futuros impactos del impuesto sobre sus negocios. No obstante, un impuesto así, con efecto anticipativo, sería tremendamente impopular y muy difícil de consensuar. De hecho, la Unión Europea no ha logrado, hasta la fecha, implantar un impuesto sobre el carbono por falta de consenso y por lo impopular que sería estar cambiando continuamente las leyes sobre la imposición.

Aquí abogamos más por un impuesto gradual, tal y como ya se ha expresado desde el principio. Nuestro argumento es que sería beneficioso un impuesto con un tipo progresivo (poco distorsionante) que no aumentara los costes de forma geométrica, pero que cambiaran a lo largo del tiempo y a medida que se van implementando las metas de emisiones. Una vez que los logros de reducción de emisiones fueran cuantiosos entonces podríamos volver a tipos impositivos bajos e, incluso eliminar el impuesto. Esto es importante, ya que los tipos impositivos deben ir ajustándose a la nueva información sobre los costes y beneficios marginales. Lo natural es que cada vez tengamos mayor y mejor información a medida que la ciencia sobre el cambio climático avanza y las nuevas tecnologías mitigadoras se ponen en marcha. La pregunta del millón es la de con qué frecuencia debemos cambiar las tipos impositivos.

Respecto a esto, la cuestión es clara y es que habrá poco beneficio derivado de ajustar los tipos en el corto plazo ya que la mayoría de las oportunidades para reducir las emisiones están relacionadas con inversiones a largo plazo, como por ejemplo la estructura industrial. En todo caso sería conveniente que

18 Metcalf, G. E. (2007) ofrece un ejemplo basado en este argumento. 
hubiera una Institución a la que delegáramos la responsabilidad de establecer las tasas del impuesto.

\section{Imposición en frontera}

Los ajustes de impuestos en frontera tienen sentido cuando nos movemos en un sistema donde los países tienen regímenes impositivos distintos Muchos países no aplican y, quizás no aplicarán nunca, impuestos sobre el carbono. El poder hacer ajustes cuando los bienes son exportados e importados es una solución para que todos los países paguen por el consumo de bienes con contenido en carbono. Cuando los bienes producidos en un país que no impone gravámenes sobre el carbono se importan a un país que sí grava estos productos se produce una ventaja comparativa para los productos no gravados en relación a los que se producen en los países con imposición sobre el carbono. Esta ventaja potencial radica en menores costes de producción relativos que tienen los países que no gravan el contenido de carbono. Un ajuste impositivo en frontera consistirá en gravar los productos importados (en función de su contenido de carbono) procedentes de países que no gravan el contenido de carbono. El caso contrario se produce cuando productos gravados previamente se exportan a países que gravan el carbono. En ese caso dichos países deberían tener una compensación en frontera para no incurrir en una doble imposición.

De todas formas, lo más complicado de estos ajustes fronterizos es determinar el contenido de carbono de los bienes importados. Este problema es especialmente importante en el caso de los países no pertenecientes al Anexo I del Convenio marco sobre Cambio Climático (China y otros países en desarrollo con marcado carácter exportador). Estos países no elaboran regularmente inventarios detallados sobre emisiones de carbono, lo que dificulta enormemente la determinación del contenido de carbono de sus productos exportados. Posiblemente, tampoco aceptarían ponerle un precio al carbono.

\section{Conclusiones}

Un objetivo importante de cualquier política destinada a paliar los efectos nocivos de la contaminación ambiental (en concreto la atmosférica) debe ser que ésta sea coste-eficiente, esto es, que pueda obtenerse la reducción máxima de emisiones para un nivel dado de gasto. Saber si sería necesaria la acción preventiva depende de cómo sea la relación entre los costes de evitar las emisiones de gases invernadero y los daños que estos gases pueden ocasionar si continúan sin ser sometidos a ningún control.

Una cuestión primordial para poder comparar impuestos sobre el carbono y permisos de emisiones desde el punto de vista de la eficiencia es la información. Si los agentes económicos tienen información sobre el coste del instrumento destinado a reducir las emisiones y sobre los costes sociales de 
las mismas (daños ambientales), entonces ambos instrumentos podrían lograr la misma reducción de la contaminación y al mismo coste.

Cuando la información no es perfecta, los agentes económicos desconocen los costes marginales de las distintas fuentes de contaminación. En este caso, no esperamos que el mercado ofrezca un precio uniforme. No ofrece igual resultado gravar las emisiones con un impuesto que establecer un sistema de permisos. Dicha elección dependerá, fundamentalmente, de las elasticidades de la curva de coste marginal (de reducir las emisiones) y de la curva de daño marginal.

Un impuesto sobre las emisiones ofrece incentivos más fuertes para desarrollar y aplicar nuevas y más limpias tecnologías que una política basada en el control cuantitativo de las mismas. El impuesto es capaz de conseguir un recorte neto de las emisiones de carbono, ya que las empresas, con el fin de reducir la cuantía del impuesto, tendrán un incentivo adicional para reducir sus emisiones.

Por último, es preciso tener en cuenta que, el cambio climático constituye uno de los mayores fracasos atribuibles al mercado, fracaso que entra en interacción con otras imperfecciones del mercado. Toda respuesta global eficaz requerirá, al menos, tres elementos de política económica: el precio del carbono, aplicado por medio de impuestos, comercio de emisiones o reglamentación; una política de apoyo a la innovación y a la aplicación de tecnologías bajas en carbono; y finalmente, la adopción de medidas para eliminar cualquier barrera a la eficiencia energética e informar, educar y persuadir a los individuos sobre lo que pueden hacer, a nivel individual, para responder al cambio climático. Claramente, el cambio climático exige una respuesta internacional, cimentada sobre una comprensión compartida de objetivos a largo plazo y un acuerdo sobre los marcos para la acción. 


\section{REFERENCIAS}

BARRET, S (1991). "Global Warming: Economics of a Carbon Tax", en Pearce, D. et al., (1991). Blueprint 2 ( $2^{\mathrm{a}}$ parte de Blueprint for a Green Economy, 1989). Eartscan Publications Limited, Londres, (pp. 31-51).

BRUVOLL, A., and B. M. LARSEN (2004): "Greenhouse Gas Emissions in Norway: Do Carbon Taxes Work?,”. Energy Policy, 32, 493-505.

CARLSON, C., and G. E. METCALF (2008): "Energy Tax Incentives and the Alternative Minimum Tax," National Tax Journal, 61, 477-491.

CLARK, L. E., J. A. EDMONDS, H. D. JACOBY, H. M. PITCHER, J. REILLY, and R.G. RICHELS (2007): "Scenarios of Greenhouse Gas Emissions and Atmopheric Concentrations, Synthesis and Assessment Product 2.1a.

CLINE, W.R. (1992). The Economics of Global Warming. Institute for International Economics. Washinton DC.

CLARKE, R., BOERO, G., y WINTERS, L.A. (1996). "Controlling Greenhouse Gases: A Survey of Global Macroeconomic Studies". Bull. Econ. Res., Octubre, 48 (4), pp. 269-308.

COMISIÓN EUROPEA (2011). "A Resource-efficient Europe. Flagship Initiative under the Europe 2020 Strategy". Comunicación de la Comisión Europea $\operatorname{COM}(2011) 21$.

- (2011a): "A Roadmap for moving to a competitive low -carbon economy in 20150". COM(2011) 112/4.

CONVERY, F. J., and L. REDMOND (2007): "Market and Price Developments in the European Union Emissions Trading Scheme". Review of Environmental Economics and Policy, 1, 88-111.

FULLERTON, D., and G. E. METCALF (1998): "Environmental Taxed and the Double-Dividend Hypothesis: Did You Really Expect Something for Nothing?," Chicago-Kent Law Review, 73, 221-256.

GARCÍA, C (2011). "El Cambio Climático: los aspectos científicos y económicos más relevantes". Nómadas. Revista Crítica de Ciencias Sociales y Jurídicas | 32 (2011.4)

- (2010). "La Evidencia del Cambio Climático. La necesidad de las Políticas Preventivas". Nómadas (25). Revista Crítica de Ciencias Sociales y Jurídicas. 
- (2010). "Los costes de la política de cambio climático: una aproximación teórica". Revista Crítica de Ciencias sociales y jurídicas.

- (2009). "La Economía del Cambio climático: las políticas preventivas y sus costes". Revista CIP-ECOSOCIAL. Boletín ECOS nº 9.

- (2008). "Comparación entre Impuestos sobre el Carbono y Permisos de emisiones en el Marco de la Eficiencia económica: una evaluación teórica". Anales de Economía Aplicada, $\mathrm{n}^{\circ}$ XXII.

- (2006). "El Análisis coste-beneficio y la dificultad de su aplicación al cambio climático". Revista Estudios de Economía Aplicada.

- (2001). "El cambio climático: análisis de las causas" y "El cambio climático análisis de los impactos". UEM. Ediciones.

- (1999). "El Cambio Climático: Estado de la Cuestión y Aspectos Científicos". DT 8/99. UEM-CEES Ediciones. Nómadas. Revista Crítica de Ciencias Sociales y Jurídicas | 32 (2011.4)

GRUBB, M (2010). "Copenhagen, back to the future?. In Climate Policy, Vol. 10, núm 2.

IPCC (2007a). "Summary for Policymakers", en IPCC, Climate Change 2007: The Physical Science Basis: Contribution of Working Group I to the Fourth Assessment Report of thelntergovernmental Panel on Climate Change (Cambridge: Cambridge University Press, 2007).

IPCC (2007b). "Summary for Policymakers", en IPCC, Climate Change 2007: Impacts, Adaptation and Vulnerability. Contribution of Working Group II to the Fourth Assessment Report of the Intergovernmental Panel on Climate Change, (Cambridge: Cambridge University Press, 2007).

JORGENSON, D.W, y WILCOXEN, P.J. (1990). "The Cost of Controlling US Carbon Dioxide Emissions". Harvard University, Cambridge, MA.

KESICKI, F (2010). "Marginal Abatement Cost Curves for Policy Making-ExpertBased vs Model-Derived Curves". Energy Institute, University College London.

METCALF, G. E., S. PALSTEV, J. REILlY, H. D. JACOBY, and J. HOLAK (2008):

"Analysis of U.S. Greenhouse Gas Tax Proposals," Cambridge: MIT.

METCALF, G. E., S. PALTSEV, J. M. REILLY, H. D. JACOBY, A. GURGEL, A. SOKOLOV, and J. HOLAK (2008): "Analysis of a Carbon Tax to Reduce U.S. Greenhouse Gas Emissions," Cambridge, MA: MIT Joint Program on the Science and Policy of Global Change.

METCALF, G. E., and J. M. REILLY (2008): "Policy Options for Controlling Greenhouse Gas Emissions: Implications for Agriculture,"Choices, 
23, 34-37.

METCALF, G.E and WEISBACH D. (2009): " The Design of a Carbon Tax". The Law school of University of Chicago. Working paper $n^{\circ} 254$.

NORDHAUS, W. (2002). "After Kyoto: Alternative Mechanisms to Control Global Warming". Yale University.

NORDHAUS, W. D. (2007): "To Tax or Not to Tax: Alternative Approaches to Slowing Global Warming,". Review of Environmental Economics and Policy, 1, 26-44.

PALTSEV, S; REILLY, J.M; JACOBY, H.D (2005). "The MIT Emissions Prediction and Policy Analysis (EPPA) Model: version 4. Massachusetts Institute of Technology.

PIGOU, A. C. (1938): The Economics of Welfare. London: Weidenfeld and Nicolson.

POTERBA, J. (1991). "Tax policy to Combat Global Warming: On Designing a Carbon Tax". En Global Warming: Economic Policy Approaches. Editado por Dornbush, R.D. y Poterba, J.M, pp. 72-98. Cambridge, MA:MIT Press.

REILLY, J., H. D. JACOBY, and R. G. PRINN (2003): "Multi-Gas Contributors to Global Climate Change, Climate Impacts and Mitigation Costs,".

Pew Center on Global Climate Change.

STERN, N. 2006. Stern Review on the Economics of Climate Change. Disponible en www.sternreview.org.uk

STERN, N. (2007): The Economics of Climate Change, the Stern Review. Cambridge, UK: Cambridge University Press

UNFCCC Press release (2010). UN Climate Change Conference in Cancun delivers balanced package of decisions, restores faith in multilateral process. Cancun, México, 11 diciembre de 2010.

- UNFCCC documentos oficiales: www.unfccc.int.

WHALLEY, J. y WIGLE, R. (2002). " Cutting CO2 Emissions: The Effects of Alternative Policy Approaches"en International Trade and Environment, Judith Dean (ed). Ashgate Publishers.

WILLIAM D. COLLINS, CECILIA M. BITZ, MAURICE L. BLACKMON (2005). "The Community Climate System Model Version 3 (CCSM3)". Journal of Climate, vol, 19.

WORLD RESOURCES INSTITUTE (1995). Informe. The Right Climate for Carbon Taxes: Creating Economic Incentives to Protect the Atmosphere. WORLD RESOURCES INSTITUTE (2006): "Climate Analysis Indicators Tool, Online Database Version 3.0". World Resources Institute. 


\section{ANEXO 1}

Table 2. Carbon Tax Rates.

\begin{tabular}{lccc}
\hline & \multicolumn{3}{c}{$\mathbf{C O}_{2}$-e Price $\left(\mathbf{\$} / \mathbf{t C O}_{\mathbf{2}}\right.$-e) } \\
& Dingell & Stark & Larson \\
\hline $\mathbf{2 0 1 5}$ & 14 & 10 & 20 \\
$\mathbf{2 0 2 0}$ & 14 & 23 & 32 \\
$\mathbf{2 0 2 5}$ & 14 & 34 & 52 \\
$\mathbf{2 0 3 0}$ & 14 & 43 & 83 \\
$\mathbf{2 0 3 5}$ & 14 & 51 & 134 \\
$\mathbf{2 0 4 0}$ & 14 & 58 & 216 \\
$\mathbf{2 0 4 5}$ & 14 & 64 & 348 \\
$\mathbf{2 0 5 0}$ & 14 & 69 & 561 \\
\hline
\end{tabular}

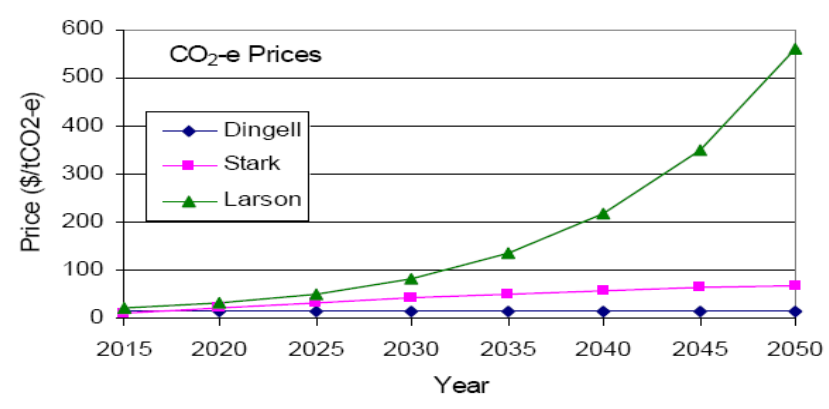

Figure 1. Carbon Tax Rates in the Core Scenarios.

Fuente: Metcalf et al (2008).

Distintas estimaciones de impuestos sobre el carbono (distintas tasas impositivas) dan lugar a diferentes trayectorias de reducción de emisiones:

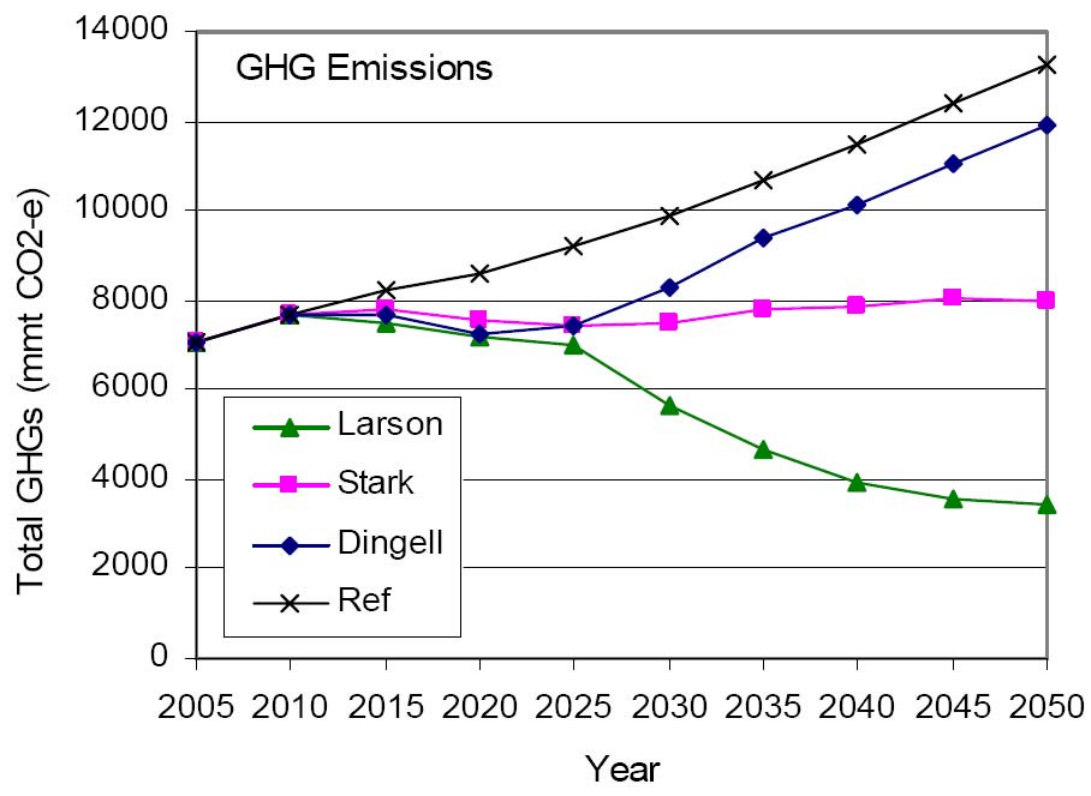

Figure 2. Total GHG emissions for core proposals 
Dichas estimaciones de la tasa impositiva dan lugar a modificaciones en el bienestar, medido este por la pérdida de consumo (en el mercado) que acarrea el impuesto y compensado por la ganancia en ocio y tiempo libre que lleva consigo (ocio asociado a pérdidas de empleos):

Table 4. Welfare Changes.

\begin{tabular}{lccc}
\hline & \multicolumn{3}{c}{ Welfare Changes (\%) } \\
& Dingell & Stark & Larson \\
\hline $\mathbf{2 0 1 5}$ & 0.01 & 0.01 & 0.01 \\
$\mathbf{2 0 2 0}$ & -0.09 & -0.09 & -0.16 \\
$\mathbf{2 0 2 5}$ & -0.25 & -0.27 & -0.24 \\
$\mathbf{2 0 3 0}$ & -0.21 & -0.39 & -0.74 \\
$\mathbf{2 0 3 5}$ & 0.07 & -0.32 & -1.25 \\
$\mathbf{2 0 4 0}$ & 0.21 & -0.38 & -1.71 \\
$\mathbf{2 0 4 5}$ & 0.32 & -0.38 & -2.08 \\
$\mathbf{2 0 5 0}$ & 0.49 & -0.33 & -2.23 \\
\hline $\mathbf{2 0 1 2 - 2 0 1 5}$ & 0.10 & -0.30 & -1.21 \\
\hline
\end{tabular}

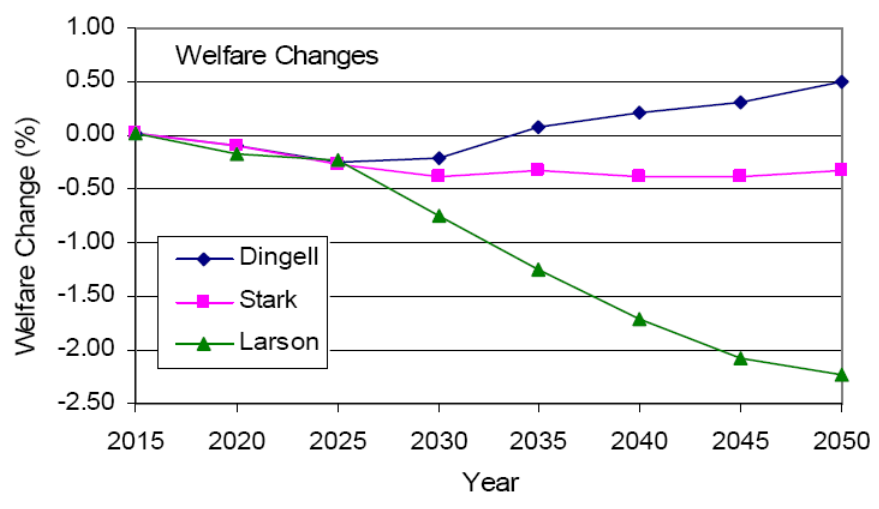

Fuente: Estos resultados pueden encontrarse en Metcalf et al, (2008), donde los autores hacen una interpretación rigurosa del modelo de la EPPA (Emissions Prediction and Policy Analysis). Este modelo puede encontrarse en Paltsev et al (2005) en su versión $n^{\circ} 4$. 
Cambios en los precios del combustible asociados a un impuesto de 27 dólares por tonelada de carbono:

ble 5. Relation between a $\sim 27 /$ ton $\mathrm{CO}_{2}$ Tax and Fuel Prices.

\begin{tabular}{rccc}
\hline Fuel & $\begin{array}{c}\text { Base Price } \\
\text { Ave. 2002- } \\
\mathbf{2 0 0 6} \\
\mathbf{( 2 0 0 5 \$ )}\end{array}$ & $\begin{array}{c}\text { Added } \\
\text { Cost (\$) }\end{array}$ & $\begin{array}{c}\text { Added Cost } \\
\mathbf{( \% )}\end{array}$ \\
\hline Crude Oil (\$/bbl) & $\$ 40.00$ & $\$ 12.20$ & $30 \%$ \\
Regular Gasoline (\$/gal) & $\$ 1.82$ & $\$ 0.26$ & $14 \%$ \\
Heating Oil (\$/gal) & $\$ 1.35$ & $\$ 0.29$ & $21 \%$ \\
Wellhead Natural Gas (\$/tcf) & $\$ 5.40$ & $\$ 1.49$ & $28 \%$ \\
Residential Natural Gas (\$/tcf) & $\$ 11.05$ & $\$ 1.50$ & $14 \%$ \\
Utility Coal (\$/short ton) & $\$ 26.70$ & $\$ 55.30$ & $207 \%$
\end{tabular}

Source: U.S. average prices for 2001-2006 computed from DOE EIA price data. Base cost price is the 5-year (2002-2006) average price, except coal (2001-2005). To the gasoline price we have added $\$ 0.42$ to include the federal and an average of state gasoline excise taxes.

The percentage price increases for fuels will vary from the estimates in Table $5 \mathrm{a}$

Incidencia del impuesto en el consumo de combustibles fósiles:

Table 6. Consumer Share of Carbon Tax Burden.

\begin{tabular}{lccccccc}
\hline & $\mathbf{2 0 1 5}$ & $\mathbf{2 0 2 0}$ & $\mathbf{2 0 2 5}$ & $\mathbf{2 0 3 0}$ & $\mathbf{2 0 3 5}$ & $\mathbf{2 0 4 0}$ & $\mathbf{2 0 4 5}$ \\
\hline Coal & & & & & & & \\
Dingell & 0.97 & 0.95 & 0.91 & 0.93 & 0.93 & 0.93 & 0.94 \\
Stark & 0.97 & 0.97 & 0.95 & 0.95 & 0.96 & 0.97 & 0.98 \\
Larson & 0.98 & 0.97 & 0.97 & 0.97 & 0.98 & 0.99 & 1.00 \\
287 bmt & 0.98 & 0.97 & 0.94 & 0.94 & 0.95 & 0.96 & 0.97 \\
Natural Gas & & & & & & & \\
Dingell & 0.78 & 1.25 & 2.88 & 2.23 & 2.30 & 2.27 & 2.19 \\
Stark & 0.79 & 1.01 & 1.75 & 2.03 & 2.01 & 1.28 & 0.86 \\
Larson & 0.78 & 0.98 & 1.43 & 1.33 & 0.94 & 0.73 & 0.60 \\
287 bmt & 0.73 & 0.98 & 2.14 & 2.52 & 1.85 & 1.49 & 0.73 \\
Crude Oil & & & & & & & \\
Dingell & 0.78 & 0.67 & 0.07 & 0.02 & 0.55 & 0.60 & 0.70 \\
Stark & 0.74 & 0.76 & 0.53 & 0.58 & 0.74 & 0.74 & 0.75 \\
Larson & 0.81 & 0.81 & 0.66 & 0.61 & 0.72 & 0.78 & 0.84 \\
287 bmt & 0.89 & 0.87 & 0.85 & 0.84 & 0.80 & 0.78 & 0.77 \\
\hline
\end{tabular}




\section{ANEXO 2}

\section{IMPUESTOS SOBRE EL CARBONO EN EL MUNDO}

\begin{tabular}{|c|c|c|}
\hline Country/Province/Mun. & Tax Name & Enactment \\
\hline Sweden & $\begin{array}{l}\mathrm{CO}_{2} \text { levy on heating and } \\
\text { process fuels }\end{array}$ & 2008 \\
\hline Finland & $\begin{array}{l}\text { Charge on exceeding of GHG } \\
\text { emission limits }\end{array}$ & 2004 \\
\hline \multirow[t]{3}{*}{ Norway } & $\mathrm{CO}_{2}$-tax on mineral products & 1991 \\
\hline & $\begin{array}{l}\text { Environmental tax on } \\
\text { greenhouse gases - HFC and } \\
\text { PFC }\end{array}$ & 2003 \\
\hline & $\begin{array}{l}\text { Tax on } \mathrm{CO}_{2} \text { emissions in } \\
\text { petroleum activities on the } \\
\text { continental shelf }\end{array}$ & 1991 \\
\hline Denmark & Duty on $\mathrm{CO}_{2}$ & 1998 \\
\hline Quebec, Canada & Hydrocarbon Duty & 2008 \\
\hline British Columbia, Canada & Carbon Tax & 2008 \\
\hline $\begin{array}{l}\text { City of Boulder, Colorado, } \\
\text { USA }\end{array}$ & Carbon Tax & $2006^{32}$ \\
\hline $\begin{array}{l}\text { San Francisco Bay Area, } \\
\text { California, USA }\end{array}$ & Carbon Tax on Businesses & $2008^{33}$ \\
\hline $\begin{array}{l}\text { Montgomery County, } \\
\text { Maryland, USA }\end{array}$ & $\begin{array}{l}\text { Carbon Tax on Stationary } \\
\text { Sources }\end{array}$ & $2010^{34}$ \\
\hline
\end{tabular}

$\mathrm{OECD} / \mathrm{EEA}$ Database on Instruments used for Environmental Policy and Natural Resources Management, available at http://www2.oecd.org/ecoinst/queries/index.htm. 